\title{
Commentary: Ventricular assist devices in small ventricles: Framing the challenge
}

\author{
James K. Kirklin, MD
}

\footnotetext{
From the Division of Cardiothoracic Surgery, Department of Surgery, Kirklin Institute for Research in Surgical Outcomes (KIRSO), The University of Alabama at Birmingham, Birmingham, Ala.

Disclosures: Author received a one-time payment of \$2500 from Xeltis as the chair of the DSMB Clinical trial of Pediatric Valved Conduit. On behalf of the Society of Thoracic Surgeons (noncommercial organization), he receives partial salary paid to his institution and serves as the Director of the Intermacs MCS Registry Data Center.

Received for publication Jan 23, 2019; accepted for publication Jan 23, 2019; available ahead of print March 7, 2019.

Address for reprints: James K. Kirklin, MD, Division of Cardiothoracic Surgery, Department of Surgery, Kirklin Institute for Research in Surgical Outcomes (KIRSO), UAB, The University of Alabama at Birmingham, THT 721, 1900 University Blvd, Birmingham, AL 35294 (E-mail: jkirklin@uabmc.edu).

J Thorac Cardiovasc Surg 2019;157:2311-2 $0022-5223 / \$ 36.00$

Copyright (C) 2019 Published by Elsevier Inc. on behalf of The American Association for Thoracic Surgery https://doi.org/10.1016/j.jtcvs.2019.01.087
}

Current generation continuous-flow (CF) left ventricular assist devices (LVADs) have provided exceptional survival for patients dying of advanced heart failure, with 1- and 2year survivals with device support exceeding $80 \%$ and $70 \%$, respectively. In this issue of the Journal, Kawabori and colleagues ${ }^{1}$ have identified an approximately $15 \%$ decrease in survival and $10 \%$ increase in stroke within 1 year among patients with a left ventricular end-diastolic dimension smaller than $6 \mathrm{~cm}$ receiving a HeartMate II (Abbott, Lake Bluff, Ill) LVAD.

Whether the findings for the HeartMate II are generalizable to the HVAD (Medtronic, Minneapolis, Minn) and the HeartMate 3 (Abbott, Lake Bluff, Ill) CF devices is important, because these are the most commonly used LVADs today. A multi-institutional analysis by Shah and associates $^{2}$ found a relationship between decreased ventricular size and increased mortality for both the HVAD and the HeartMate II, but no specific cut point was identified. ${ }^{2}$ No specific analyses have targeted the interaction between survival and left ventricular size with the HeartMate 3.

What conditions are most likely to be affected? Certain cardiomyopathies are characterized by restrictive physiology and smaller ventricular size, including hypertrophic cardiomyopathy, amyloidosis, sarcoidosis, and radiationinduced restrictive cardiomyopathy. In these conditions, heart failure is typically characterized by a mixture of systolic and diastolic dysfunction and only moderate ventricular dilation. When patients with these conditions develop progressive life-threatening heart failure, no therapy short of mechanical support is effective unless rapid heart transplantation occurs. Furthermore, small women, children, and adolescents with a variety of advanced heart failure conditions are increasingly receiving CF LVAD support, most commonly with the HVAD. ${ }^{3}$ Many of these patients have a ventricle smaller than $6 \mathrm{~cm}$.

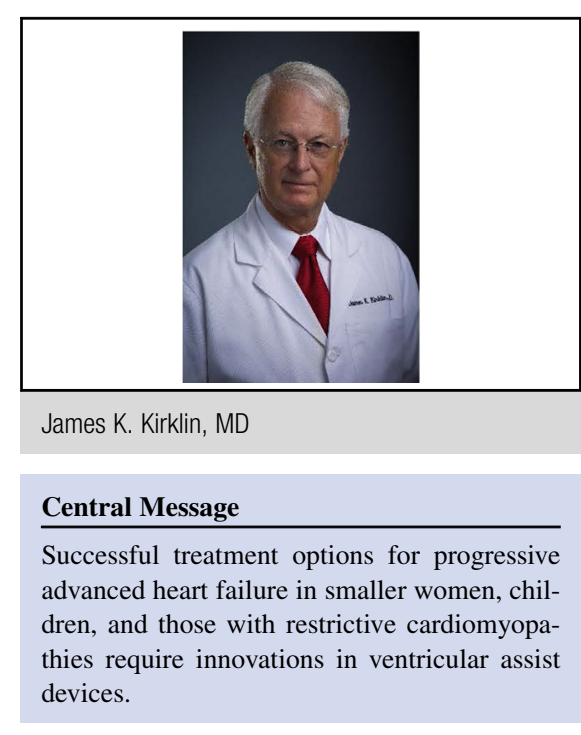

See Article page 2302.

Can we neutralize the risk with a "perfect operation"? In the domain of mechanical circulatory support in smaller ventricles, "perfect" refers to an apical cannula that is positioned half way between the interventricular septum and the lateral wall and is directly facing the mitral orifice. Kawabori and colleagues ${ }^{1}$ were not able to analyze the potential impact of perfect versus imperfect cannula position. Future studies should focus on the possibility of improved outcomes (mortality and freedom from stroke) in patients who have a perfectly positioned left ventricular inflow cannula and on how such positioning was achieved. For example, with the HVAD device, controversy remains regarding the best external location for the apical cannula. Whereas some surgeons prefer direct apical cannulation, others believe that the diaphragmatic surface of the left ventricle near the apex provides the most direct access to the mitral valve orifice. Topilsky, Park, and colleagues ${ }^{4,5}$ have written extensively about optimizing the use of LVADs in patients with restrictive cardiomyopathy.

Finally, what are the implications for affected patients? Despite the identification of a smaller ventricle as a risk factor for death and stroke, this finding should not be interpreted as an indication for excluding such patients from LVAD therapy. Rather, the challenge is to find ways to neutralize the risk associated with small ventricular size, 
because patients with restrictive cardiomyopathy in whom advanced heart failure develops often have a worse prognosis than do those with more dilated ventricles. We need devices more amenable to smaller ventricular spaces, reproducible methods to achieve perfect cannula positioning, and tailored management algorithms to optimize LVAD performance.

We may gain insights from the pediatric LVAD experience. An increasing application of the HVAD in pediatric patients has generated 1-year survival exceeding $80 \%$, with similar survival among children smaller than $20 \mathrm{~kg} .{ }^{3}$ Experience is also emerging with the use of the HeartMate 3 in pediatric patients. Unfortunately, specific data are lacking about the range of ventricular sizes in those implants, but smaller left ventricular size would be anticipated. More detailed analyses of the pediatric CF LVAD experience thus may provide useful insights about device types and implant techniques that are most generalizable to the adult with a less dilated left ventricle.

\section{References}

1. Kawabori M, Kurihara C, Conyer R, Sugiura T, Critsinelis BS, Lee VV, et al. A left ventricular end-diastolic dimension less than $6.0 \mathrm{~cm}$ is associated with mortality after implantation of an axial-flow pump. J Thorac Cardiovasc Surg. 2019;157: 2302-10.

2. Shah P, Birk S, Maltais S, Stulak J, Elmi A, Pagani FD, et al. Left ventricular assist device outcomes based on flow configuration and pre-operative left ventricular dimension: an interagency registry for mechanically assisted circulatory support analysis. J Heart Lung Transplant. 2017;36:640-9.

3. VanderPluym CJ, Adachi I, Niebler R, Griffiths E, Fynn-Thompson F, Chen S, et al. Outcomes of children supported with an intracorporeal continuous-flow left ventricular assist system. J Heart Lung Transplant. September 25, 2018 [Epub ahead of print].

4. Topilsky Y, Pereira NL, Shah DK, Boilson B, Schirger JA, Kushwaha SS, et al. Left ventricular assist device therapy in patients with restrictive and hypertrophic cardiomyopathy. Circ Heart Fail. 2011;4:266-75.

5. Grupper A, Park SJ, Pereira NL, Schettle SD, Gerber Y, Topilsky Y, et al. Role of ventricular assist therapy for patients with heart failure and restrictive physiology: improving outcomes for a lethal disease. J Heart Lung Transplant. 2015;34: 1042-9. 